\title{
As práticas em educação ambiental nas escolas do campo em comunidades insulares
}

\author{
Environmental education practices in rural schools in island communities \\ Prácticas de educación ambiental en escuelas rurales en comunidades \\ insulares
}

\author{
Helena Midori Kashiwagi ${ }^{1}$ \\ Luciane Godoy Bonafini ${ }^{2}$
}

\begin{abstract}
Resumo
O artigo aborda a Educação Ambiental no contexto da Educação do Campo, em especial nas comunidades insulares, com o objetivo de apresentar a incorporação da Política Nacional de Educação Ambiental, nas ações e práticas pedagógicas em Educação Ambiental desenvolvidas nas Escolas do Campo das comunidades insulares de Paranaguá, município do litoral do Paraná. Fundamentou-se nos aportes legais das Diretrizes e Bases da Educação Nacional para compreender a política educacional da Educação do Campo e as flexibilizações no Projeto Pedagógico do Curso a partir da adequação curricular e metodologias apropriadas ao meio rural. A pesquisa foi desenvolvida utilizando-se os aportes teórico-metodológico da pesquisa-ação-participante, a problematização com o arco de Maguerez, os temas geradores e a aprendizagem por projetos, para a proposição das práticas em Educação Ambiental. Os resultados apontam que a diversidade social, cultural, econômica e ambiental, são propulsores para repensar a Educação do Campo em comunidades insulares.
\end{abstract}

Palavras Chaves: Autonomia. Currículo. Diversidade. Projetos. Parcerias.

\begin{abstract}
The article approaches Environmental Education in the context of Rural Education, especially in island communities, with the objective of presenting the incorporation of the National Environmental Education Policy, in the pedagogical actions and practices in Environmental Education developed in rural schools of Paranaguá island communities. , municipality on the coast of Paraná. It was based on the legal contributions of the National Education Guidelines and Bases to understand the educational policy of Rural Education and the flexibilities in the pedagogical project of the course based on the curricular adequacy and methodologies appropriate to the rural environment. The research was developed using the theoretical-methodological contributions of participant-action-research, the problematization with the Maguerez arc, the generating themes and the learning by projects, for the proposition of practices in Environmental Education. The results show that social, cultural, economic and environmental diversity are impeller to rethink rural education in island communities.
\end{abstract}

Keywords: Autonomy. Resume. Diversity. Projects. Partnerships.

\section{Resumen}

El artículo aborda la Educación Ambiental en el contexto de la Educación Rural, especialmente en las comunidades insulares, con el objetivo de presentar la incorporación de la Política Nacional de Educación Ambiental, en las acciones y prácticas pedagógicas en Educación Ambiental desarrolladas en las Escuelas del Campo de la isla. comunidades de Paranaguá, municipio de la costa de Paraná. Se basó en los aportes legales de los Lineamientos y Bases Educativas Nacionales para comprender la política educativa de Educación Rural y las flexibilidades en el Proyecto Pedagógico del Curso desde la adecuación curricular y metodologías adecuadas al medio rural. La investigación se desarrolló

\footnotetext{
1 Universidade Federal do Paraná.

2 Prefeitura Municipal de Paranaguá.
} 
utilizando los aportes teórico-metodológicos de la investigación acción participante, la problematización con el arco de Maguerez, los temas generadores y el aprendizaje por proyectos, para la proposición de prácticas en Educación Ambiental. Los resultados muestran que la diversidad social, cultural, económica y ambiental son fuerzas impulsoras para repensar la educación rural en las comunidades insulares.

Palabras Clave: Autonomía. Plan de estudios. Diversidad. Proyectos. Asociaciones.

\section{Introdução}

Falar sobre a Educação Ambiental no contexto da Educação do Campo, em especial nas comunidades insulares, remete compreender como a Política Nacional de Educação Ambiental, Lei Federal n. 9795/99, foi sendo incorporada na Política Educacional das Escolas do Campo e a inclusão de práticas em Educação Ambiental nos Projetos Pedagógicos de Curso das Escolas do Campo em comunidades isoladas geograficamente e com acesso exclusivo pelo mar. O objetivo desse artigo é apresentar a incorporação da Política de Educação Ambiental nas ações e práticas pedagógicas em Educação Ambiental desenvolvidas aos alunos das Escolas do Campo das comunidades insulares de Paranaguá, município do litoral do Paraná.

A política educacional sobre a Educação do Campo ganha visibilidade ao ser incluída na Lei de Diretrizes e Bases da Educação Nacional (LDB), Lei Federal n. 9394/1996, em seu artigo 28, o qual possibilita a adequação curricular e metodologias apropriadas ao meio rural, e flexibilização da organização escolar, com adequação do calendário escolar à natureza do trabalho na zona rural. Nas comunidades rurais a dimensão ambiental é aprendida de forma diferenciada, além dos muros da escola, em que proteger e preservar a natureza, o uso equilibrado dos recursos naturais, são valores construídos nas vivencias cotidianas e repassados de geração em geração (BRASIL, 1996).

A política de Educação do Campo torna-se mais evidente e valorizada quando o governo federal aprova o Decreto n. 7352 de 4 de novembro de 2010, o qual dispõe sobre a autonomia das Escolas do Campo para elaborar seu próprio Projeto Pedagógico de Curso (PPC) para ensinar a Educação Ambiental respeitando os conteúdos culturais, saberes rurais, tradições locais vinculadas às causas, aos desafios, aos sonhos e à cultura dos povos que vivem no campo. Busca-se, nessa autonomia, veicular um saber significativo, crítico, contextualizado, do qual se extraem indicadores para a ação, reforçando um projeto político-pedagógico vinculado a uma cultura política libertária, baseada em valores como a solidariedade, igualdade e diversidade (BRASIL, 2010).

Percebe-se a existência de um papel político da Educação Ambiental no âmbito escolar do campo, em que se contextualiza as temáticas ambientais com os problemas locais de forma interdisciplinar. Situa-se a Educação Ambiental no projeto educativo das escolas, fortalecendo a relação do ser humano com a natureza e a reconstrução do sistema de relações entre as pessoas, a sociedade e o ambiente natural. Nas escolas do campo, a Educação Ambiental é diferenciada, articulada às demandas e as especificidades de cada território, de cada localidade e a realidade socioambiental-econômica de cada comunidade. A postura do professor nas escolas do campo, diante das práticas de Educação Ambiental, assume uma postura política desenvolvida a partir de novos paradigmas ambientais e educacionais.

O professor das escolas do campo, com a sua autonomia pedagógica, procura adotar uma abordagem mais humanística, democrática e participativa na concepção dos seus métodos de ensino-aprendizagem, vindo ao encontro com os princípios básicos da Política Nacional de Educação Ambiental. Com uma perspectiva inter, multi e transdisciplinar, o professor procura conceber o meio ambiente na sua totalidade, na interdependência entre o meio natural, socio-econômico e cultural, sob o enfoque da sustentabilidade. As práticas em Educação Ambiental são articuladas as questões ambientais locais, regionais, nacionais e globais, reconhecendo e respeitando a pluralidade e a diversidade individual e cultural (BRASIL, 1999). 
Essa postura do professor nos remete as práticas pedagógicas e ao pensamento Freireano como uma referência significativa para a Educação Ambiental, em função de sua vocação problematizadora, o rompimento do senso comum, a superação de uma educação conteudista, acrítica, o enfrentamento e a superação das formas de opressão, adotando um pensamento que se preocupa com a forma do indivíduo se relacionar com o meio ambiente e na construção de um outro mundo sem armadilhas paradigmáticas. O ensinar exige respeito aos saberes dos alunos e a valorização das suas experiências cotidianas, especialmente, em salas multisseriadas como nas escolas do campo, onde se encontram crianças de diferentes idades e com visões de mundo peculiares sobre o contexto ambiental (FREIRE, 2019).

As turmas multisseriadas exigem um olhar especial do professor na construção das práticas pedagógicas, na metodologia a ser utilizada em sala de aula. Cada aluno tem seu tempo de aprendizagem e ritmos diferentes de apreensão do conhecimento, com visões e percepções de mundo ainda fundadas nas experiências dentro do universo familiar. Com esses desafios no cotidiano escolar do professor das escolas do campo, a Educação Ambiental tem sido abordada a partir de temas geradores e a interdisciplinaridade como ferramenta pedagógica para o desenvolvimento na apreensão do conhecimento. A utilização de uma metodologia baseada nos temas geradores visa superar a pedagogia tradicional, cujo conhecimento é transmitido, exclusivamente, por quem sabe "o educador" para quem não sabe "o educando". Por meio dos temas geradores é possível construir de forma dinâmica os conhecimentos, os já apropriados e os que serão construídos, de forma coletiva, participativa, contextualizada, interdisciplinar, promovendo uma aprendizagem significativa e transformadora.

As escolas do campo, a partir dos temas geradores, ressignificam os conteúdos escolares, objetivos e métodos de ensino para promover a socialização dos alunos em seu contexto cultural, estimulando a criatividade, ludicidade relação entre a escola e família, cooperação, exercício da cidadania e interligando os conteúdos à realidade dos alunos do campo. Os temas geradores balizam a construção de projetos ambientais, os quais são desenvolvidos em sala de aula com os próprios alunos e buscam alcançar os pais e demais moradores da comunidade. Nessa pedagogia por projetos, desenvolve-se na criança argumentos críticos sobre a realidade, estimulando-a a uma nova maneira de ler o mundo e contribuir com ações de Educação Ambiental no espaço em que vivem, envolvendo as famílias e comunidades. A Pedagogia por projetos tem norteado as atividades escolares das escolas do campo nas comunidades insulares de Paranaguá, permitindo um trabalho interdisciplinar nas práticas pedagógicas em Educação Ambiental.

O contexto de análise dessa reflexão são as escolas do campo do município de Paranaguá-PR, localizadas em comunidades insulares e/ou isoladas geograficamente com acesso exclusivo pelo mar. Destacando como referência para aportar essa reflexão teórica os dados analisados na Escola Municipal do Campo Amparo (Figura 1). O município de Paranaguá possui 14 escolas do campo, sendo 9 localizadas em ambientes insulares ou com acesso exclusivo pelo mar. $O$ isolamento geográfico de algumas escolas do campo, somado a poucos recursos tecnológicos disponíveis, dificultam a execução de atividades complementares como a participação dos alunos em eventos culturais, feiras acadêmicas, exposições educativas, e outros eventos realizados no continente.

Escolheu-se apresentar neste artigo as práticas pedagógicas desenvolvidas na Escola do Campo de Amparo por estar inserida numa comunidade que, apesar de estar numa área rural próxima do centro urbano da cidade, o acesso é exclusivo pelo mar e este isolamento geográfico manteve preservada as características locais como costumes e tradições da cultura caiçara, da pesca artesanal e a relação com a natureza. Os alunos que frequentam essa Escola são filhos de pescadores, da comunidade e de outras próximas, os quais vivem em moradias simples, algumas precárias, convivendo numa realidade em que os valores são ressignificados. Os moradores da comunidade de Amparo, em sua maioria, realizam trabalhos em atividades pesqueiras e/ou trabalhos informais. Residem na comunidade 82 
famílias, com um total de 249 moradores, desses 50 são crianças e adolescentes. A comunidade possui 145 construções residenciais, 73 estão habitadas por moradores da comunidade e as demais são de veraneio. Na comunidade existem poucos comércios como uma padaria, uma lanchonete, quatro mercadinhos e dois bares. Funcionam duas escolas: uma escola municipal e outra escola estadual. Duas pequenas pousadas hospedam turistas, visitantes curiosos e pesquisadores.

Figura 1 - Localização da comunidade amparo

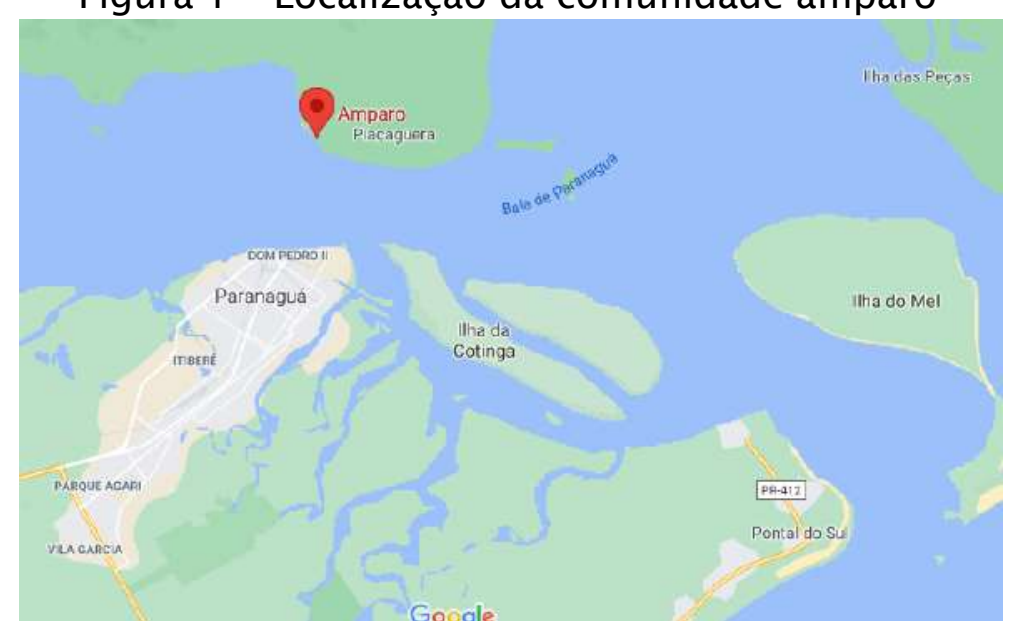

Fonte: Google Earth, 2021.

A Escola Municipal do Campo de Amparo foi criada e autorizada pela Resolução $\mathrm{n}^{\circ}$ $3.678 / 82$ de 30 de dezembro de 1982. Está localizada numa comunidade conhecida como Ilha de Amparo, no Município de Paranaguá no Estado do Paraná. Com 24 alunos, entre 6 a 10 anos, numa sala multisseriada. Há pouca evasão e repetentes, alguns casos isolados de dificuldades de aprendizagem. O Projeto Político Pedagógico da Escola Municipal do Campo Amparo está embasado na Lei de Diretrizes e Bases da Educação Nacional (LDB) nº 9394/96 que estabelece o atendimento à Educação Infantil e Ensino Fundamental. Os artigos $12^{\circ} \mathrm{e}$ $13^{\circ}$ desta Lei, citam normas que devem ser estabelecidas no sistema de ensino da escola, como a elaboração do seu Projeto Político Pedagógico. Os docentes são incumbidos de: participar da elaboração do Projeto Político Pedagógico da Escola; elaborar um plano de trabalho, segundo o projeto Político Pedagógico. Colaborar com as atividades de articulação da escola com as famílias e comunidade. Segundo o art. 28 na oferta da educação básica para a população rural, os sistemas de ensino promoverão as adaptações necessárias à sua adequação às peculiaridades da vida rural e de cada região, especialmente referente aos conteúdos curriculares e metodologias apropriadas às reais necessidades e interesses dos alunos da zona rural; Enfatizando a organização escolar própria, incluindo adequação do calendário escolar às fases do ciclo agrícola e às condições climáticas e a adequação à natureza do trabalho na zona rural.

O território da Comunidade de Amparo está inserido dentro dos limites da Área de Proteção Ambiental (APA) de Guaraqueçaba, uma Unidade de Conservação de uso sustentável, criada em 2002 pelo Decreto n. 90883 de 31 de janeiro de 1985. Não se tem registros oficiais sobre quando surgiu essa comunidade, mas sabe-se que as leis ambientais foram aprovadas independentemente da existência de muitas comunidades insulares e/ou isoladas geograficamente. A APA de Guaraqueçaba foi criada para frear a ocupação descontrolada nessa comunidade, e, principalmente, proteger uma das últimas áreas representativas da Floresta Pluvial Atlântica, onde encontram-se o complexo estuarino da Baía de Paranaguá, formado em sua parte líquida por baías, canais e enseadas, margeado por manguezais, e, em sua porção litorânea e continental, o patrimônio cultural, representado por pescadores artesanais e agricultores familiares, que vivem há mais de um 
século na região.

\section{Métodos aplicados na pesquisa}

A interdisciplinaridade proposta pela Educação Ambiental abre um leque criativo de abordagens metodológicas para a realização das ações, cujas análises ao se entrelaçarem permitem exercer os princípios da política nacional da Educação Ambiental. As especificidades das práticas de ensino observadas nas escolas do campo, implicou em arranjos metodológicos adotando-se para essa pesquisa o entrelace de alguns métodos para atingir o objetivo proposto. Nesse sentido elegemos os seguintes métodos para essa investigação: o método pesquisa-ação-participante (THIOLLENT, 1987; BRANDÃO, 1981; TOZONI-REIS, 2006; GADOTTI, 1991); método problematização com o Arco de Maguerez (BORDENAVE E PEREIRA, 2015); método temas geradores Paulo Freire (GADOTTI, 1996; LAYRARGUES, 1999); e, o método de Aprendizagem por Projetos (ALCÂNTARA, 2012).

O método pesquisa-ação-participante contribuiu para rever o papel do educador ambiental que vai além de educador e educando, mas um pesquisador que participa ativamente do grupo que realiza a ação. O núcleo social da práxis universitária se descentraliza, transcendendo a relação entre a teoria e a prática, e deixando de servir a uma única ideologia desenvolvimentista dominante para direcionar práticas de desenvolvimento local, valorizando a cultura tradicional e a ação dos sujeitos de um coletivo. Procurou-se construir uma Educação Ambiental com os conhecimentos apreendidos nas experimentações do coletivo, nas observações e vivências de mundo, realizando um processo educativo no qual todos os envolvidos, pesquisadores, educadores e comunidade, se colocam numa postura dialógica horizontalizada e interativa, gerando uma corresponsabilidade, na qual a comunidade se apodera do processo de identificação, análise e solução dos problemas socioambientais de toda a coletividade.

O método da problematização com o arco de Maguerez (Figura 2), orienta-se por uma sequência de cinco etapas: a) a primeira etapa inicia pela observação da realidade, que consiste em uma visão global do assunto/problema a ser estudado a partir da experiencia de vida e conhecimentos empíricos dos alunos; b) a segunda etapa consiste na identificação das variáveis ou pontos-chave centrais do problema, os quais se modificados podem resultar na solução do problema; c) a terceira etapa é a teorização do problema, recorrendo a leituras, pesquisas realizadas que contribuam para esclarecer o problema; d) a quarta etapa é a formulação de hipóteses de solução do problema, as quais são confrontadas com os pontos-chave do problema e as soluções mais viáveis são selecionadas; e, por último, e) a quinta etapa é a aplicação à realidade dos conhecimentos visando solucionar os problemas. No arco de Maguerez exercita-se a cadeia dialética de ação-reflexão-ação, ou, dito de outra maneira, a relação prática-teoria-prática, tendo como ponto de partida e de chegada do processo de ensino e aprendizagem, a realidade social.

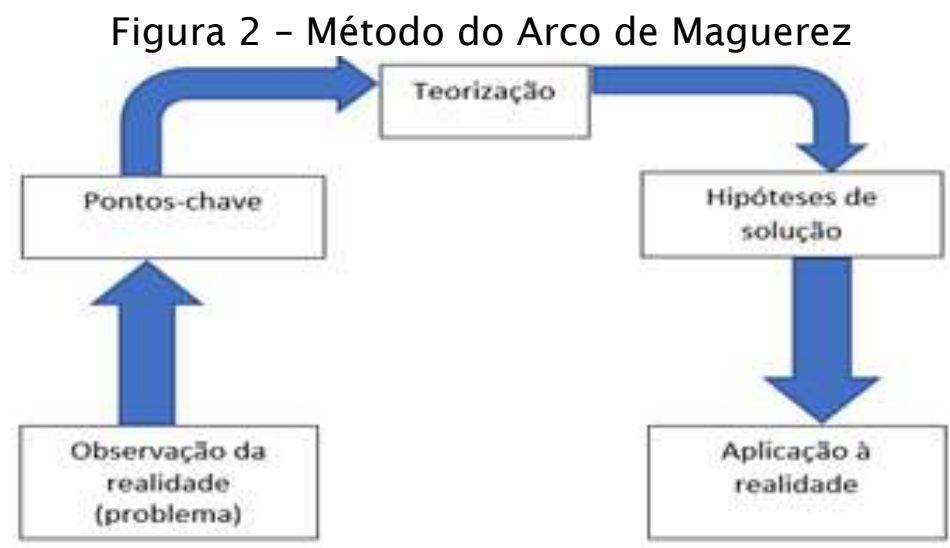

Fonte: Bordenave e Pereira, 2015. 
O método de temas geradores proposto por Paulo Freire embasa-se num conjunto de fundamentos políticos-filosóficos presentes na Educação libertadora, na qual educadores e educandos, mediatizados pelo mundo, educam-se em comunhão, rompendo com os princípios da educação tradicional. Os temas geradores só podem ser compreendidos nas relações homem-mundo, no modo de pensar e de se apropriar sobre a realidade. A investigação de um tema, no domínio humano, é um processo de busca, de conhecimento, de criação, no qual exige-se dos sujeitos na ordenação dos temas significativos, a interpenetração dos problemas. Na Educação Ambiental os temas geradores, por seu potencial reflexivo e problematizador, possibilitam a proposição de ações educativas com conteúdos socioambientais significativos para a formação crítica e transformadora dos educandos.

O método de Aprendizagem por Projetos compreende focar na aprendizagem e não apenas no conteúdo; incentivar a aprendizagem significativa buscando a motivação e o envolvimento do aluno; estabelecer uma relação entre a aprendizagem e a experiencia de vida do aluno; valorizar as características individuais; e, priorizar o aprender como um processo natural e contínuo. O professor assume uma postura de orientador, incentivador na elaboração de projetos e na gestão dos projetos, deixa de ser o transmissor de conteúdos e passa a ser o mediador da aprendizagem. Neste fazer pedagógico o aluno é instigado para buscar as soluções, tornando-se o centro da aprendizagem. Busca-se aumentar a interatividade, a autonomia, a aprendizagem contextualizada e a análise crítica do aluno, o qual se coloca como sujeito participativo no processo de criação.

\section{Resultados da implementação das práticas em Educação Ambiental}

A aparente simplicidade das escolas do campo revela uma complexidade na condução do Projeto Político do Curso, pois é evidente que, a falta de recursos tecnológicos disponíveis para acompanhar o mesmo ritmo de ensino das escolas do continente, implica em repensar a forma de ensinar. Os desafios postos ao professor das escolas do campo induzem a necessidade de capacitação docente para essa realidade "rural" e insular. Observa-se nas escolas isoladas geograficamente, alguns fatores que agravam a condução das atividades de ensino como a ausência de recursos tecnológicos como computadores, projetores multimídia, ausência de sinal para conexão da internet, acesso às comunidades somente pelo mar, ausência de alunos de outras comunidades em dias chuvosos e até mesmo da professora, salas multisseriadas com crianças de diferentes faixas etárias, além de mobiliários e imóvel da escola deteriorados por conta da maresia. Diante deste cenário, o professor urge por recorrer a outros métodos e processos de ensino-aprendizagem, especialmente, no desenvolvimento das ações em Educação Ambiental de forma coletiva.

A autonomia na elaboração do Projeto Político do Curso foi decisiva para incentivar os professores das escolas do campo a repensar o ensinar, elaborando ações pedagógicas a partir dos recursos disponíveis, com mais ludicidade e envolvendo todos os alunos e a comunidade. A valorização da relação dos alunos com o território, a conexão com a natureza, os costumes e cultura local, foram fundamentais para nortear e propor 0 entrelaçado de métodos para implementar as ações pedagógicas em Educação Ambiental. Como referencial de análise para aportar essa reflexão teórica destacou-se as práticas exitosas em Educação Ambiental realizadas na Escola Municipal do Campo Amparo. Para abordar essas práticas foi preciso considerar as características sociais, ambientais e educacionais das Escolas do Campo em comunidades isoladas geograficamente e/ou insulares.

Diante deste cenário ambiental, os professores da Escola Municipal do Campo Amparo iniciaram em 2018 um projeto com a intenção de formar cidadãos ambientalmente mais conscientes e solidários, com foco especial na formação dessa consciência ambiental nas crianças da comunidade. O projeto teve como objetivo promover tanto na escola, como na comunidade, meios e ações de conscientização e cidadania, sobre os impactos e 
problemáticas ambientais locais e globais. O desenvolvimento de atividades escolares para a formação ambiental dessas crianças foi uma maneira de orientar os alunos num percurso investigativo para a resolução das problemáticas ambientais ou para encontrar as respostas norteadoras, ligadas as etapas da pesquisa, discussões em grupos de estudo, realização de atividades práticas, entre outras propostas.

A atividades do projeto foram inseridas no Projeto Pedagógico do Curso, desenvolvidas uma vez por semana, as quintas-feiras, em período integral com as turmas do segundo ao quinto ano, permitindo, dessa forma, que todos os 24 alunos da Escola pudessem participar e se envolver com o projeto, bem como funcionários, professores da escola, pais dos alunos e a comunidade em geral. O projeto foi desenvolvido na parte da manhã atividades teóricas, em sala, sobre os conteúdos abordados e na parte da tarde atividades práticas, externas, no espaço da escola e na comunidade. O planejamento dos temas a serem abordados e as práticas eram construídos com os alunos e aplicados na semana seguinte. As atividades desenvolvidas foram produção textual relacionados ao meio ambiente, roda de conversa entre os alunos e com moradores, aulas de campo para observação da natureza, construção de maquetes, execução de lixeiras ecológicas, confecção de placas educativas, mutirões de limpeza do entorno escolar, da comunidade e dos caminhos, mutirões de coleta de resíduos recicláveis, manuseio da horta escolar, entre outras atividades.

O trabalho com "projeto" e incluindo essa atividade no Projeto Pedagógico do Curso foi uma forma de integrar diferentes disciplinas e turmas multisseriadas, permeando a Educação Ambiental de forma inter, multi e transdisciplinar nas diversas atividades. Buscouse proporcionar a visão crítica nos alunos, a participação ativa, a observação da realidade, reflexões acerca das problemáticas ambientais, a valorização dos conhecimentos dos próprios alunos e a construção de novos pensamentos para a elaboração de ações locais. Articulou-se diferentes métodos de pesquisa durante o desenvolvimento desse projeto, o método da problematização com o arco de Maguerez e os temas geradores norteiam toda a pesquisa, com o método da pesquisa-ação-participante perpassando em todas as atividades e o método de aprendizagem por projeto, como sujeito entrelaçando de forma interdisciplinar todas as ações em Educação Ambiental.

$\mathrm{Na}$ sala de aula, iniciou-se o processo de ensino com a primeira etapa do método de problematização do Arco de Maguerez, Observação da Realidade para identificar um ou mais problemas, articulando-se com o método dos temas geradores de Paulo Freire. Os alunos participaram de forma ativa, dialogando sobre os saberes empíricos e experiencias individuais, relatando as visões de mundo com base nos valores e conhecimentos repassados pelos pais. Com essa reflexão foram sendo despertados novos olhares sobre a realidade local e aos poucos foram sendo revelados as problemáticas locais, num processo dialógico uns com os outros e com os professores.

A etapa seguinte foi identificar os Pontos-Chave dos problemas identificados, apontando as variáveis a partir da observação da realidade concreta. Alunos, professores, pais de alunos, nas vivências práticas e conversas com os moradores, constataram entre alguns moradores a falta de consciência ambiental e descaso com o meio ambiente, ao destinarem o lixo domiciliar no rio, mar e manguezais. A falta de saneamento ambiental e a ausência da coleta de lixo regular nas comunidades insulares são alguns dos problemas ambientais que tem instigado os professores das escolas do campo na busca por inovações nas práticas de ensino e nas ações pedagógicas em Educação Ambiental. Diante dessa constatação, os professores perceberam a importância de trabalhar a consciência ambiental partindo da escola para a comunidade e originou-se o projeto "Formação de agentes ambientais mirins".

Na terceira etapa Maguerez propõe a Teorização das constatações observadas, nesta fase os alunos são orientados a buscar embasamento teórico em livros, revistas, e, outras fontes apresentadas em sala, a fim de construir uma explanação teórica do problema de forma coletiva. Para colaborar nessa teorização dos problemas, os professores convidaram profissionais, voluntários, para compartilhar experiências e conhecimentos relacionados aos 
temas. Nessas palestras, durante os debates coletivos, os alunos despertaram a curiosidade em pensar sobre as hipóteses de soluções para as problemáticas levantadas.

Na proposição das Hipóteses de Soluções os alunos discutem as problemáticas, as quais são conferidas e selecionadas conforme a viabilidade de aplicação das soluções a partir de ações em Educação Ambiental e, o impacto de transformação da realidade ou de mudança comportamental de uma coletividade. Uma das problemáticas mais significativas para os alunos foram o lixo e esgoto lançados nos córregos, nos mangues e no mar, causando a poluição ambiental e diversas doenças de transmissão hídrica.

A última etapa do Arco de Maguerez é a Aplicação à Realidade, nessa fase procurouse observar se os alunos adquiriram novos conhecimentos com os debates realizados nos momentos de teorização e se os conteúdos programáticos abordados foram aplicados à sua realidade, visando disseminar a consciência ambiental e a solução dos problemas levantados. Nessa etapa, verificou-se mudanças comportamentais de forma gradativa nos alunos, considerando cada ação exitosa em Educação Ambiental desenvolvida nas atividades individuais e coletivas.

Uma das práticas de aplicação à realidade relevante e significativa para os alunos foi a organização de uma exposição na escola (Figura 3) sobre os trabalhos pedagógicos com a temática ambiental, aberto a comunidade e convidados da Secretaria Municipal de Meio Ambiente, Saúde e Educação da Prefeitura de Paranaguá. Nesse evento os alunos apresentaram o projeto desenvolvido, maquetes e artesanatos com materiais reciclados, pinturas em cartazes com temas ambientais, fotografias das ações em Educação Ambiental desenvolvidas, retratando soluções propostas para algumas problemáticas locais.

Figura 3 - Exposição dos trabalhos dos alunos

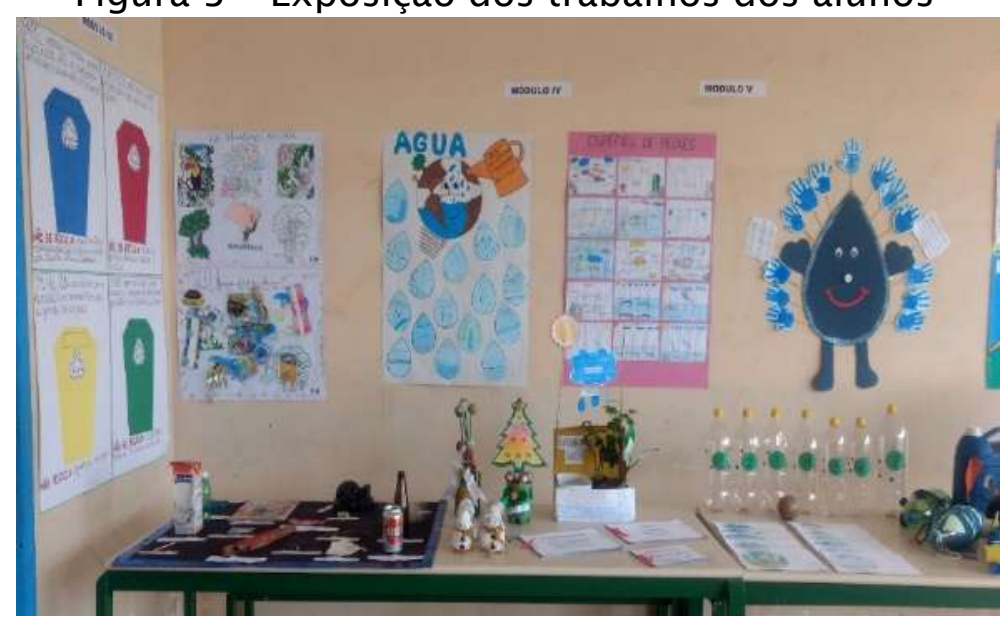

FONTE: A autora, 2018.

Esse evento apresentou os resultados de todas as ações e práticas em Educação Ambiental desenvolvidas pelos alunos no ano de 2018 , o projeto de formação de agentes ambientais mirins foi incorporado pela comunidade com a mudança comportamental e consciência ambiental dos moradores. O projeto atraiu parceiros, empresas da região, interessados em apoiar os projetos ambientais e as ações em Educação Ambiental na comunidade. Os pais dos alunos ressignificaram a Escola, considerando-a como espaço para debater os problemas ambientais e buscar soluções com a intervenção da escola na comunidade.

\section{Discussões e desafios sobre as práticas em Educação Ambiental em Amparo}

O contexto ambiental no qual as escolas do campo estão inseridas propicia atividades extracurriculares com maior contato com a natureza. $\mathrm{O}$ ambiente natural é referenciado nas práticas de ensino, adotando-se exemplos da vida cotidiana para abordar os conteúdos 
disciplinares. A flexibilização e autonomia na elaboração do Projeto Pedagógico de Curso, diferenciado, respeitando-se as especificidades locais, valores e costumes presentes nas comunidades são constatações que possibilitam ao professor adotar novas abordagens metodológicas e inovar nas suas práticas de ensino.

Nesse cenário educacional, a deficiência ou quase inexistência de recursos didáticos tecnológicos tornaram-se propulsores para a ressignificar a Educação do Campo, utilizando os recursos naturais como ferramenta pedagógica essencial na contextualização de todas as áreas de conhecimento. E é nesse contexto, interdisciplinar, que as práticas em Educação Ambiental são desenvolvidas em que o processo educativo valoriza as tradições e saberes empíricos e ambientais dos moradores locais.

Uma das práticas em Educação Ambiental exitosas, na qual os alunos intitulados agentes ambientais mirins (o projeto foi uma ação pedagógica por isso não possui uma certificação formal) foi a parceria de uma empresa portuária de Paranaguá, a qual pactuou com a proposta de ação de Educação Ambiental de coleta de lixo na comunidade e doou lixeiras para serem colocadas nas trilhas e caminhos da comunidade (Figura 4). 0 trabalho de conscientização ambiental desenvolvido com a comunidade nas reuniões nas escolas foi um facilitador para a rápida mudança comportamental, depositando os resíduos domiciliares nas lixeiras. A prefeitura passou a enviar uma vez por semana um barco para recolher o lixo da comunidade.

Figura 4 - Colocação das lixeiras na comunidade

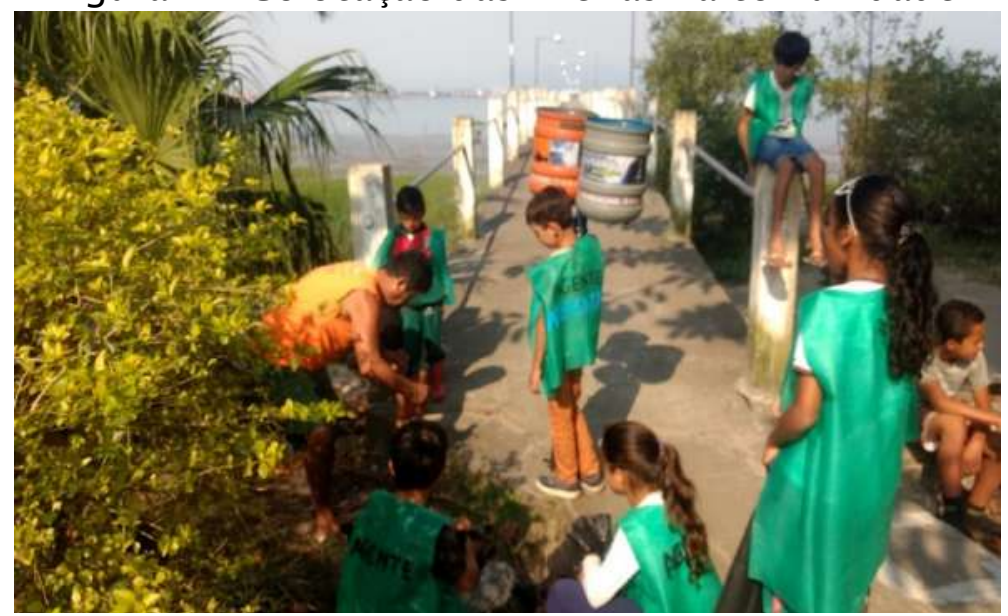

Fonte: A autora, 2018.

As comunidades isoladas geograficamente, como a comunidade de Amparo, com acesso exclusivo pelo mar, têm como primeira dificuldade a ausência de um transporte público, implicando na travessia em barcos de propriedade particular. Por esse motivo, as parcerias de empresas em projetos ambientais e voluntários para executar ações extensionistas adquirem uma dimensão imensurável no universo imaginário das crianças.

As barreiras dos desafios inatingíveis foram quebradas com a visibilidade de pequenas ações em Educação Ambiental desenvolvidas pelos alunos da Escola do Campo de Amparo, atraindo curiosos e até mesmo empresas e voluntários para participar dos projetos ambientais. Um biólogo da empresa Cia Ambiental com experiência em projetos de Educação Ambiental se prontificou em dar uma palestra na Escola, uma vez por mês, para debater diversas temáticas ambientais e colaborar nas práticas em Educação Ambiental na comunidade. A empresa AquaPlant, desenvolve na comunidade um projeto ambiental "Troca Solidária" para os moradores trocarem resíduos recicláveis por alimentos, incentivando a separação do lixo reciclável. A empresa Catallini ao conhecer o empenho dos professores da Escola do Campo de Amparo doou recursos para uma reforma e benfeitorias no prédio 
da Escola, essa ação foi muito significativa para os professores, alunos, funcionários da escola, pais dos alunos e toda a comunidade, pois para os moradores da comunidade a Escola é uma extensão do lar das famílias.

\section{Conclusão}

A incorporação da Política de Educação Ambiental nas ações e práticas pedagógicas nas Escolas do Campo em comunidades insulares de Paranaguá, com recorte referencial para aportar essa reflexão teórica, a Escola Municipal do Campo Amparo, demonstrou que a flexibilização e autonomia na elaboração do Projeto Político do Curso é um dos condicionantes para as práticas exitosas em Educação Ambiental.

O planejamento das atividades curriculares e extracurriculares nas escolas do campo, em comunidades insulares, precisa prever flexibilizações, pois as mudanças nas condições climáticas podem dificultar a navegação e prejudicar o acesso dos alunos que vem de outras comunidades e até mesmo do(a) professor(a) que vem do continente. Inclusive, as práticas regulares em Educação Ambiental precisam ser adequadas e flexibilidades de acordo com situação climática local.

Constatou-se que a deficiência e/ou ausência de recursos tecnológicos e falta de conexão com internet implicam em redirecionar as práticas pedagógicas e em Educação Ambiental utilizando-se recursos naturais disponíveis na comunidade. As atividades podem ser ressignificadas com maior ludicidade por meio de ferramentas pedagógicas sensoriais e elementos simbólicos da natureza para conectar os conhecimentos empíricos e tradicionais aos conteúdos dos livros paradidáticos.

O entrelace de diferentes métodos com abordagem qualitativa para investigar problemáticas ambientais demonstrou êxito em todo o processo educativo, no qual todos os métodos co-existiram numa postura dialógica horizontalizada e interativa entre todos os envolvidos, possibilitando da problematização de problemas as proposições de soluções viáveis aplicadas por meio de práticas pedagógicas inovadoras e práticas em Educação Ambiental exitosas dentro de um contexto e universo da Educação do Campo em comunidades insulares.

A Educação Ambiental revelou-se o eixo integrador entre os conteúdos disciplinares abordados nas turmas multisseriadas das Escolas do Campo, na qual a abordagem interdisciplinar na exemplificação de temáticas ambientais tem ressignificado a natureza, a Escola, a comunidade e todo o contexto ambiental. A consciência ambiental presente em gerações passadas é despertada com a alegria e o entusiasmo das crianças que com a postura de agentes ambientais mirins modificaram o comportamento ambiental de toda a comunidade e transformaram a realidade com pequenas práticas em Educação Ambiental.

O apoio de empresas privadas na implementação e/ou continuidade das práticas em Educação Ambiental nas comunidades insulares tem sido fundamentais para a preservação da consciência ambiental de toda a coletividade. Entretanto, é preciso conscientizar ambientalmente os políticos, governantes locais, para implementar políticas públicas ambientais que assegurem a qualidade de vida dos moradores dessas comunidades, a preservação e recuperação ambiental, com equidade e justiça social.

\section{Referências}

ALCÂNTARA, Vânia. Inserção curricular na Educação Ambiental. 1. ed. Curitiba: IESDE Brasil, 2012. 108p.

BRASIL. Lei $\mathbf{n}^{\circ}$ 9.394, de 20 de dezembro de 1996. Estabelece as Diretrizes e Bases da Educação Nacional. Brasília, DF: Presidência da República, [2021]. Disponível em: http://www.planalto.gov.br/ccivil_03/LEIS/L9394.htm. Acesso em: 26 abr. 2021.

BRASIL. Lei n 9.795, de 27 de abril de 1999. Dispõe sobre a Educação Ambiental, institui 
a Política Nacional de Educação Ambiental e dá outras providências. Brasília, DF: Presidência da República, [2021]. Disponível em: http://www.planalto.gov.br/ccivil_03/Leis/L9795.htm. Acesso em: 26 mar. 2021.

BRASIL. Decreto $n^{\circ} 7352$, de 4 de novembro de 2010. Dispõe sobre a política de Educação do Campo e o Programa Nacional de Educação na Reforma Agrária - PRONERA. Brasília, DF: Presidência da República, [2021]. Disponível em: http://www.planalto.gov.br/ccivil_03/_ato2007-2010/2010/decreto/D7352.htm. Acesso em: 26 abr. 2021.

BONAFINI, Luciane Godoy. Conscientização e educação ambiental: partindo da escola para a comunidade. 2019. Dissertação (Mestrado em Ensino das Ciências Ambientais) Setor Litoral, Universidade Federal do Paraná, Matinhos, 2019. Disponível em: https://acervodigital.ufpr.br/bitstream/handle/1 884/64614/R\%20-\%20D\%20\%20LUCIANE\%20GODOY\%20BONAFINI.pdf?sequence=1 \&isAllowed=y. Acesso em: 26 abr. 2021.

BORDENAVE, Juan Diaz; PEREIRA, Adair Martins. Estratégias de Ensino-aprendizagem. 33. ed. Petrópolis: Vozes, 2015.357p.

BRANDÃO, Carlos Rodrigues. Pesquisa participante. São Paulo: Brasiliense, 1981. 211 p.

FREIRE, Paulo. Pedagogia da autonomia: saberes necessários à prática educativa. 59. ed. Rio de Janeiro; São Paulo: Paz \& Terra, 2019. 143p.

GADOTTI, Moacir. Convite à leitura de Paulo Freire. 2. ed. São Paulo: Scipione, 1991 . $175 \mathrm{p}$.

GADOTTI, Moacir (org). Paulo Freire: uma biobibliografia. São Paulo: Editora Cortez/Instituto Paulo Freire, 1996. Disponível em:

http://acervo.paulofreire.org:8080/jspui/bitstream/7891/3078/1/FPF_PTPF_12_069.pdf. Acesso em: 10 mai. 2021.

LAYRARGUES, Philippe Pomier. P. A resolução de problemas ambientais locais deve ser um tema-gerador ou atividade-fim da educação ambiental? In: REICOTA, Marcos. (org). Verde cotidiano: o meio ambiente em discussão. Rio de Janeiro: DP\&A Editora, 1999. p.131-148.

TOZONI-REIS, Marília Freitas de Campos. Temas ambientais como "temas geradores": contribuições para uma metodologia educativa ambiental crítica, transformadora e emancipatória. In: Educar em Revista, Curitiba, n. 27, p. 93-110, jun. 2006. DOI: http://dx.doi.org/10.1590/S0104-40602006000100007.

Disponível em: https://www.scielo.br/pdf/er/n27/a07n27.pdf. Acesso em: 29 jan. 2019.

THIOLLENT, Michel. Crítica metodológica, investigação social e enquete operária. 5 ed. São Paulo: Polis, 1987. 270p. 


\section{Helena Midori Kashiwagi}

É graduada em Arquitetura e Urbanismo pela UFPR, Mestre e Doutora em Geografia pela UFPR, com estágio de Doutorado sanduíche na Universidad Autónoma de Madrid Atualmente, é professora titular da Universidade Federal do Paraná - Setor Litoral, professora de Planejamento Urbano do Curso Superior de Tecnologia em Gestão Imobiliária e Coordenadora do Mestrado Profissional em Rede Nacional para Ensino das Ciências Ambientais (PROFCIAMB) - UFPR Litoral É pesquisadora do Grupo Interdisciplinar de Estudos e Pesquisas para o Desenvolvimento Sustentável do Litoral do Paraná (CNPQ), atuando em pesquisa na área de Educação Ambiental, Escolas do Campo, Planejamento Urbano, Populações Tradicionais Caiçaras, Território e Territorialidade. E-mail: helenamkashiwagi@gmail.com. ORCID: https://orcid.org/0000-0003-2565-5428.

\section{Luciane Godoy Bonafini}

Luciane Godoy Bonafini possui graduação no curso de Pedagogia pela Universidade Estadual do Paraná - UNESPAR (2010), Especialização em Educação Ambiental pela Faculdade de Educação São Luís/SP (2017) e Mestrado no Programa de Pós-graduação em Rede Nacional para Ensino das Ciências Ambientais (PROFCIAMB) pela UFPR Litoral. Foi Orientadora de Estudos no Programa Nacional de Alfabetização na Idade Certa - PNAIC, promovido pelo Ministério da Edu-cação e Cultura, ofertado pela Universidade Federal do Paraná (2013 a 2017). É professora do Ensino Fundamental, séries iniciais, e Educação Infantil pela Prefeitura Municipal de Paranaguá na Educação do Campo há dezenove anos. E-mail: lubonafini@gmail.com. ORCID: https://orcid.org/0000-0003-3702-6741. 